\title{
“Butterfly Technique” for Breast Reduction and Lift
}

\section{D’Onofrio C*}

Plastic Surgeon Specialist, Dubai London Clinic \& Speciality Hospital, UAE

*Corresponding author: Crescenzo D’Onofrio, Dubai London Clinic \& Speciality Hospital, Jumeira Road, Dubai, UAE, Tel: +971 56 1362455; Email: crescenzo.donofrio@gmail.com

\section{Research Article}

Volume 3 Issue 2

Received Date: August 13, 2019

Published Date: September 04, 2019

DOI: $10.23880 /$ ijtps-16000133

\section{Abstract}

The Author introduce his original technique valid for a wide range of breast ptosis and hypertrophy, and give new input for a tailored procedure. A butterfly shaped incision is made on the breast lower quadrants, leaving intact a central block, while medial and lateral excisions are performed. The central glandular-dermal flap is then transposed, overloading the two residual (lateral and medial) flaps advanced to the middle line, and is anchored to the pectoralis fascia. The volumes, so restored in shape and projection, are now lifting and supporting the gland by an internal double dermal brassiere.

Keywords: Breast reduction; Mastopexy; Breast hypertrophy

\section{Introduction}

We believe that Benelli [1] "round block" technique and Lassus/Lejour [2] vertical technique constitute a very important step in Breast Reduction and Lift surgery as they give a new input for the technique evolu- tion toward more reliable results.

Many efforts have been done from many authors [3-6] to achieve a better shape and projection with shorter scar. Our preference was first for the Ramirez [7] "owl" incision which we adopted until 2005, when we made some substantial modifications and original adjuncts to this technique. Our butterfly technique combines basic principles with original elements, improving the plasticity and naturalness of results.

\section{Surgical Technique}

\section{Preoperative Marking}

On the breast meridian (Figure 1abc) we fix point A which is the projection of the inframammary line midpoint 0 . Then we identify point $B$, which is at $7-8 \mathrm{~cm}$ from point 0 , on the breast meridian. Point $\mathrm{C}-\mathrm{D}$ and $\mathrm{E}-\mathrm{F}$ are identified by the surgeon evaluation, according to the breast size and skin excess (Figure 1).

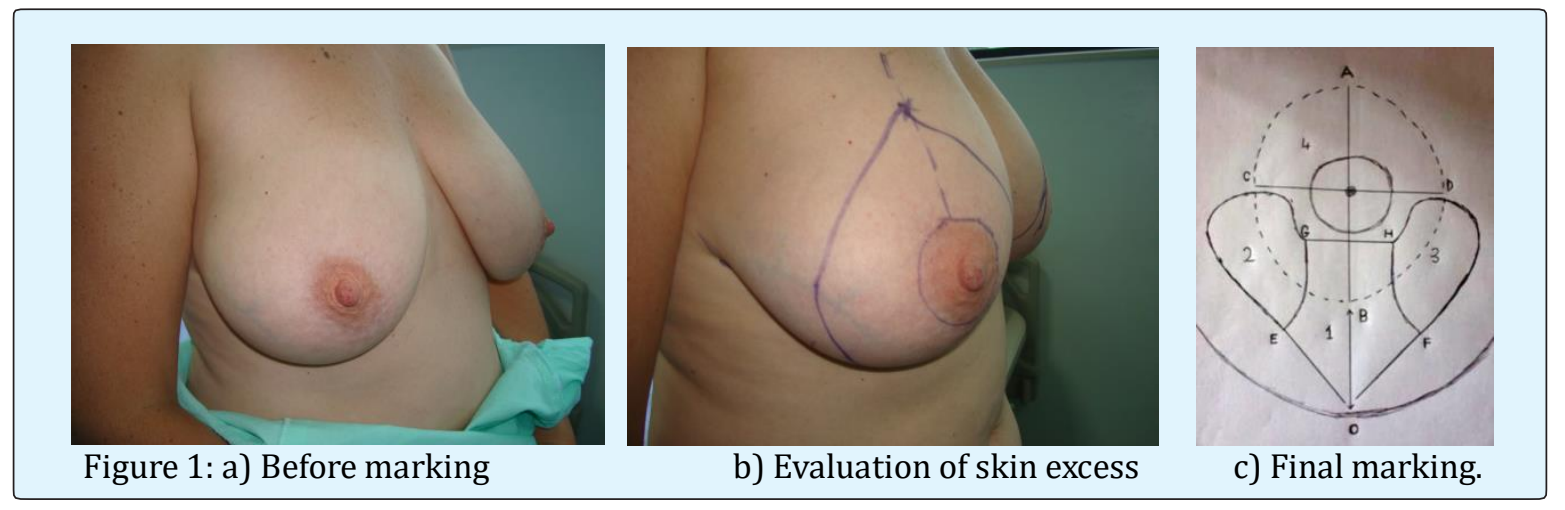




\section{International Journal of Transplantation \& Plastic Surgery}

We outline the area so determined and the circumference of the new areola (about $4 \mathrm{~cm}$ diameter) (Figure 1). About $1 \mathrm{~cm}$ from the areola inferior border we draw the projection of areola diameter (GH). Joining $\mathrm{G}$ with $\mathrm{E}$ and $\mathrm{H}$ with $\mathrm{F}$ we outline the central block and we call it Area 1 (Figure 1c). From $\mathrm{G}$ and $\mathrm{H}$ we draw a curved line with the top at about $1 \mathrm{~cm}$ from $\mathrm{CD}$, then down to reach $\mathrm{E}$ and $\mathrm{F}$ (Figure 1). In this way we outline the area 2 and 3 . We call 4 the remaining area. The final draw will have a butterfly shape (Figure 1c).

\section{Local Infiltration}

We perform all procedures under tumescent local anesthesia (30cc lydocaine $2 \%, 0.5 \mathrm{ml}$ adrenaline, 300cc saline solution) with general sedation. This technique allows us to obtain a clean surgical field with minimum bleeding, a quick recovery, and less discomfort in the postoperative period.

\section{Incisions}

The areas 1-2-3 and 4 are now de-epithelialized (Figure 2a) while the incision goes deeply along areas 2 and 3 (Figure $2 b \& c$ ), leaving intact the derma, for lateral and medial volume reduction. The excision is performed in a vertical plane, leaving intact the central block 1 (Figure 3abc), and should never cross the imaginary vertical plane passing by $\mathrm{CD}$, with exception for selected cases of major hypertrophy. The next step consists of mobilizing the central block and to lift it up (Figure 2d); the lateral and medial volumes are then advanced toward the middle line and the two dermal internal borders are joined by vycril 3-0 to create an internal dermal support to the gland and to prevent a new ptosis.

The lifted central flap can now overload the dermal brassiere and can be anchored to the fascia (Figure 2e), enforcing even more the dermal brassiere and giving a natural contour. Joining $\mathrm{OE}$ with $\mathrm{OF}$ a new breast is sculptured, with soft and natural shape (Figure 3a).

The periareolar area is softly and naturally delimitated so that the last step is the subdermal and skin suture by monocryl 4-0 and vicryl rapid 5-0, with very few external stitches (Figure 3a). The final scar will be vertical for most of the cases. Elongated and very flattened breasts will require an adjunctive $10 \mathrm{~cm}$ horizontal scar.

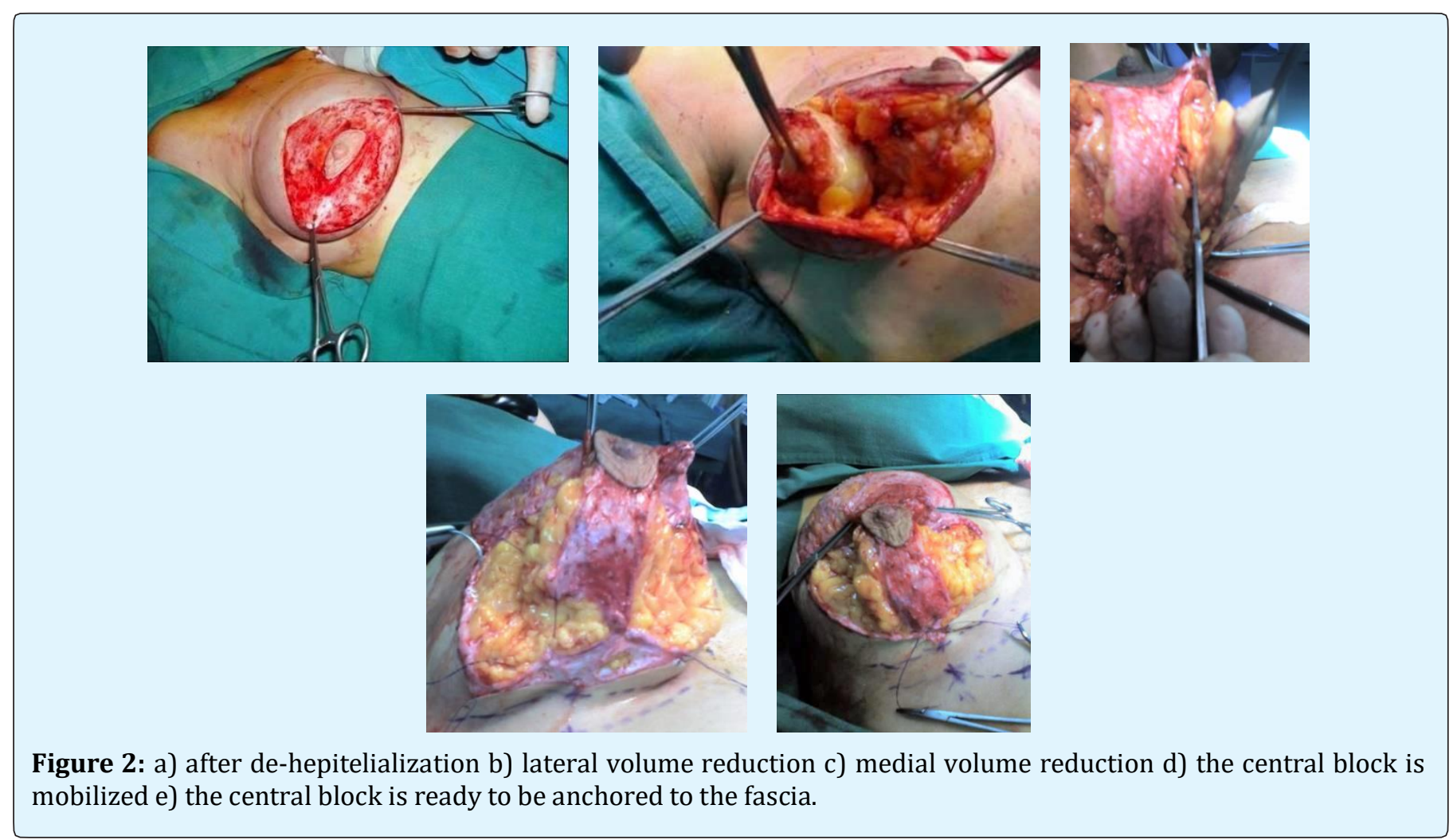

D’Onofrio C. "Butterfly Technique" for Breast Reduction and Lift. Int J Transplant \& Plastic Surg 2019, 3(2): 000133. 


\section{International Journal of Transplantation \& Plastic Surgery}

\section{Discussion}

Many techniques have been used to reduce the breast ptosis, associated or not with breast hypertrophy, with diversified approaches 8), 9), 10), 11), 12); yet still today the problem is debated. Most of the surgical procedures in use are directed toward correction of minor or moderate ptosis, while the majority of patients with ptosis have an accentuated degree of pendulous flattened breast 13). Most of the difficulties arise in codifying a procedure valid for all range of breast ptosis, from minor to major14); our technique, based on a volume relocation concept, is original, simple and very effective with all range of ptosis and hypertrophy.

\section{Conclusion}

The breast volumes, so relocated, combine together in a restored harmonic shape, immediately after surgery. In this way we diminish the lateral fullness, while giving a good projection and an inferior natural contour, without pleating or flattening effect (Figure 3a).

The technique can be easily performed, following a correct preoperative marking and a correct skin and volume excess evaluation; yet in the hands of expert surgeons an asymmetric marking and volume reduction (more laterally than medially) can be accomplished, with very gratifying result(Figures $3 b-3 i$ ).
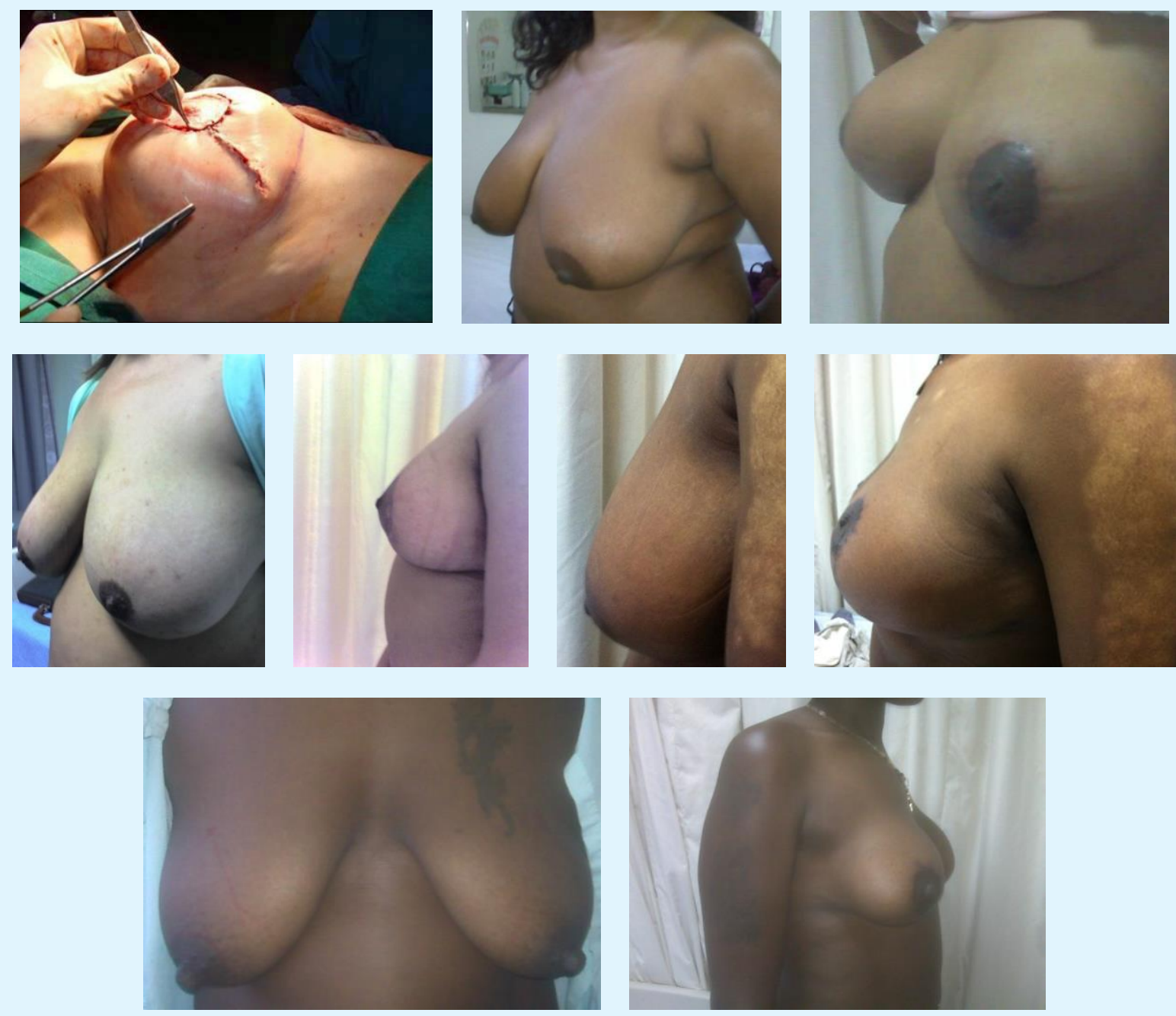

Figure 3: a) final shape and skin suture, b-c) medium hypertrophy before-after, d-e) major hypertrophy before-after, f-g) minor hipertrophy before-after, h-i) elongated flattened breast before-after. 


\section{International Journal of Transplantation \& Plastic Surgery}

We believe that breast reduction surgery, claiming the importance of rigid scientific evaluation, is projected toward a new era as well, giving evidence to the artistic component of our specialty.

Our experience, since May 2006, is now consolidated, with a range of tissue excision from about $200 \mathrm{gr}$. to 1400gr. The maximum follow up was one year. We had few minor complications only. Most of the patients were satisfied immediately after surgery, especially for shape and projection.

\section{References}

1. Benelli L (1990) A new periareolar mammaplasty: The "round block" technique. Aesthetic Plast Surg 14(2): 93-100.

2. Lejour M (1996) Vertical mammaplasty for breast hypertrophy and ptosis. Op. Techn. In Pl.Rec. Surg. 3(3): 189-198.

3. Asplund OA, Davies DM (1996) Vertical scar breast reduction with medial flap or glandular transposition of the nipple areola. British Journal of Plastic Surgery 49(8): 507-514.

4. Wallach SG (2006) Technical refinements of the vertical mammaplasty: A modified Lejour approach. Aesthetic Surgery Journal 26(2): 179-187.

5. Mottura A (2000) Circumvertical reduction mastoplasty. Aesthetic Surgery Journal 20(3): 199204.

6. Serra-Renom JM, Fontdevila J (2004) New marking designs for vertical scar breast reduction. Aesthet Surg J 24(2): 171-175.
7. Ramirez OM (2002) Reduction mammaplasty with the "owl" incision and no undermining. Plast Reconstr Surg 109(2): 512-522.

8. Goulian D Jr (1976) Dermal mastopexy. Clin Plast Surg 3(2): 171-175.

9. Gruber RP, Jones HW Jr (1980) The "donut" mastopexy: indications and complications. Plast. Reconstruct Surg 65(1): 34-38.

10. Becker H (2001) The Dermal Overlap Subareolar Mastopexy: A Preliminary Report. Aesthet Surg J 21(5): 423-427.

11. Goes JC (2003) Periareolar mastopexy: Double skin technique with mesh support. Aesthet Surg J 23(2): 129-135.

12. De la Plaza R, De la Cruz L, Moreno C (2005) Mastopexy utilizing a dermoglandular hammock flap. Aesthet Surg J 25(1): 31-36.

13. Rubin JP (2006) Mastopexy after massive weight loss: Dermal suspension and total parenchymal reshaping. Aesthet Surg J 26(2): 214-222.

14. Biggs TM, Graf R, Taneja A (2003) Maintaining shape in mastopexy. Aesthet Surg J 23(5): 391-392.

15. Hudson DA, Moodley S (2017) Breast Reduction: Decreasing Complications and Improving Long-Term Aesthetic Results with Parenchymal Sutures. Plast Reconstr Surg Glob Open 5(9): e1470. 